\title{
The environmental research field site "Horkheimer Insel": Research program, instrumentation and first results
}

\section{Le site de recherche sur l'environment "Horkheimer Insel": Programme de recherche, instrumentation et premiers résultats}

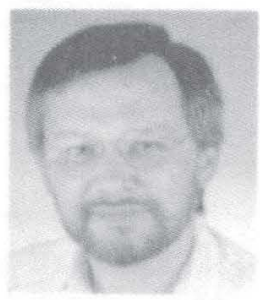

\author{
G. TEUTSCH \\ Instifut für Wasserbau, University of Stuttgart, \\ Stuttgant, Fed. Rep. of Germany
}

\author{
H. KOBUS \\ Institut für Wasserbau, Universiry of Stutgart, \\ Stutrgart, Fed. Rep. of Germany
}

\begin{abstract}
In order to carry out soil and groundwater related field experiments under controlled natural conditions, an environmental research test site has been set up in July 1987 on the "Horkheimer Insel", $70 \mathrm{~km}$ north of Stuttgart.

At present, the interdisciplinary research program comprises one groundwater project, two projects dealing with the unsaturated zone and the soil, and one environmental database project. The 2 ha field site is extensively instrumented, comprising 24 multilevel groundwater observation- and pumping-wells, a large monolithic lysimeter, a meterological station, as well as numerous tensiometer and suction cups. In order to facilitate the communication and data exchange between the cooperating university institutes, a distributed database system is being developed. During the initial phase of the investigations, the field site has been extensively described in terms of underground structure, as well as the soil and aquifer parameters. The investigation program is presented together with first results of the ongoing field experiments,
\end{abstract}

\section{RÉSUMÉ}

Afin d'effectuer des expériences combinées sol-eaux souterraines dans des conditions naturelles controlées, un site-test de recherche sur l'environnement a été équipé en juillet 1987 sur l'île "Horkheimer Insel", située à $70 \mathrm{~km}$ au nord de Stuttgart.

A l'heure actuelle, le programme de recherche interdisciplinaire comprend un projet sur les eaux souterraines, deux projets portant sur la żone nonsaturée et le sol ainsi qu'un projet sur la constitution d'un base de données sur l'environnement. Le site expérimental de 2 ha est instrumenté de façon extensive et comprend 24 puits de captage et d'observation à différents niveaux, un lysimétre à grand diamètre, une station météorologique, ainsi que de nombreux tensiométres et bougies poreuses. Dans le but de faciliter la communication et l'échange de données entre les instituts des universités impliquées, un système de base de données a été développé. Pendant la phase initiale des investigations, le site a été décrit de façon extensive en terme de structure du sol et du sous-sol et de paramètres de l'aquifere. Le programme d'investigations et les premiers résultats des expériences se déroulant sur le terrain sont preséntés ici.

\section{Introduction}

It is generally accepted that environmental research programs require an interdisciplinary approach. This is especially true for soil and groundwater quality investigations where numerous complex chemical, biological and hydromechanical processes and their interactions have to be analysed.

Revision received December 12, 1989. Open for discussion till February 28, 1991 . 
Furthermore, in environmental research programs the problem of choosing the appropriate scale of investigation often arises. Regional field investigations generally provide inadequate or incomplete data sets and are very time consuming, whereas laboratory studies generally fail to reproduce field conditions. Properly designed field experiments under controlled conditions are therefore considered a preferred alternative. Due to the considerable infrastructure usually involved, these experiments are costly; however they are likely to provide the best possible results in terms of data diversity, data resolution and completeness, as well as data quality.

Based on this concept and a feasibility study prepared by the Institut für Wasserbau at Stuttgart University [3], the PWAB (Projekt Wasser-Abfall-Boden) scientific committee decided to support financially the set up of an environmental research field site on the "Horkheimer Insel", $70 \mathrm{~km}$ north of Stuttgart.

Fig. 1 shows a block diagram of the northern area of the site. The entire site covers an area of about 2 ha, situated between the Neckar canal in the east and the Neckar river in the west. The aquifer is formed by 2 to 5 meters of alluvial sand and gravel and is overlain by silty clays and loam with thicknesses ranging between 4 and 5 meters. Intercalated mud- and limestones form the underlying aquiclude at depths between 8 and 9 meters below ground surface. The alluvial aquifer is generally unconfined with piezometric levels ranging between 5 and 6 meters below ground.

Since July 1987 an interdisciplinary research program is conducted at the experimental site, the overall objective of this program being the development and improvement of soil and groundwater protection methods. Participating researchers are hydrogeologists, civil engineers, agri-

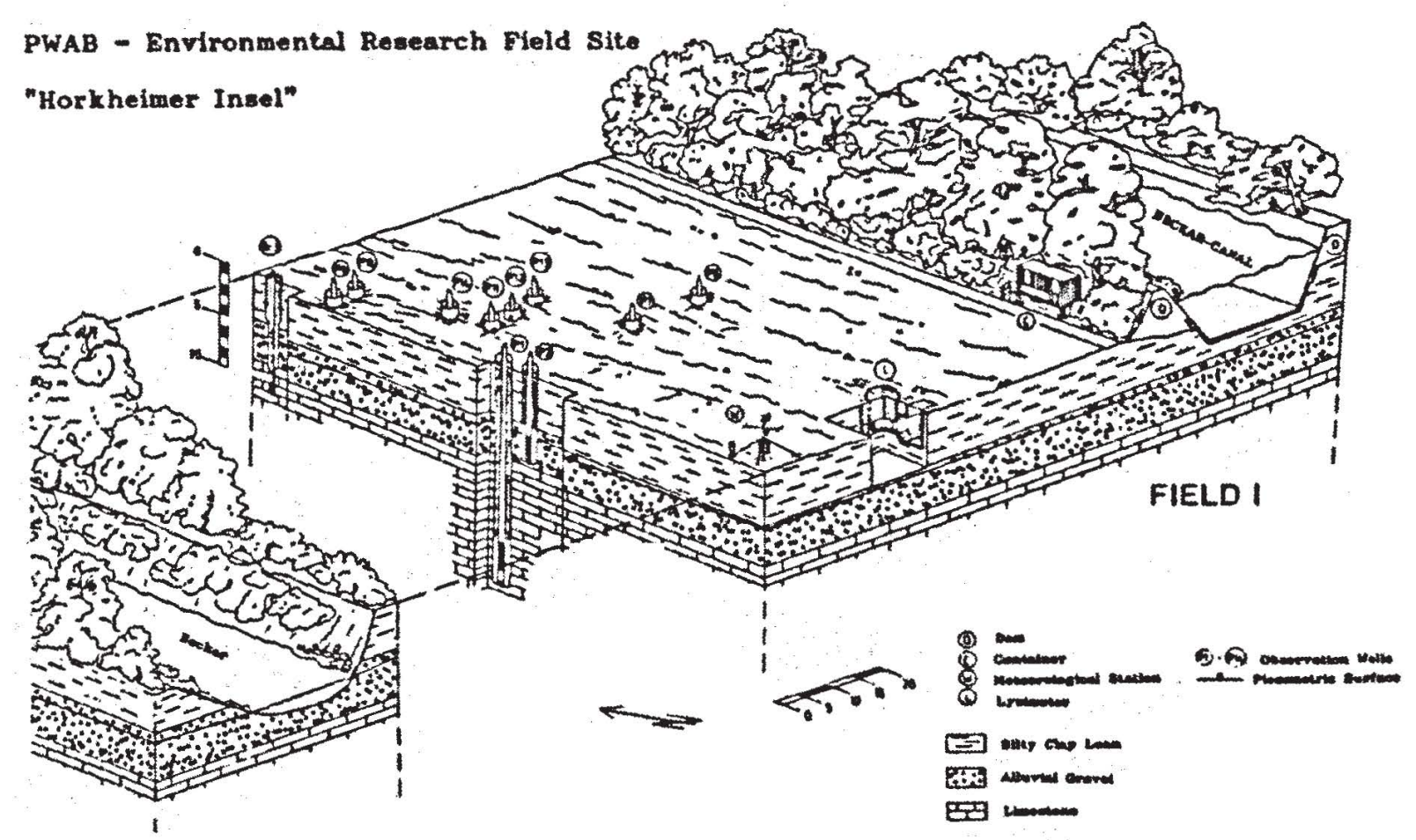

Fig. 1. The "Horkheimer Insel" environmental research field site (northern field). Le site de recherche sur l'environnement "Horkheimer Insel" (champ nord). 
cultural engineers, agrobiologists, chemists, and computer scientists. The work is organized in four projects at three universities in Baden-Württemberg, each project covering a different aspect of the "Horkheimer Insel" research program [1].

One project deals with the groundwater contamination assessment and rehabilitation problems encountered in agricultural and industrial areas. Two projects investigate the water quality in the unsaturated zone comparing conventional and low-agrochemicals farming techniques. The last project organises the entire data-administration aspects employing a specially adapted environmental database system.

\section{Projects}

Development of measuring-, investigation-, and monitoring-methods for the detection and evaluation of groundwater and soil contaminations (Institut für Wasserbau, University of Stutgart).

A prerequisite for soil or groundwater contamination assessment or for contamination risk analyses is the determination of the underground structure, together with the governing underground parameters and their variability. At the "Horkheimer Insel" experimental site a number of different underground investigation and measuring methods are employed in parallel for comparison purposes. They include drilling, surface and borehole geophysics, pumping-tests, tracer-tests, and laboratory measurements. The information redundancy obtained through the parallel application of the methods will help to define practical guidelines for future soil and groundwater contamination studies. These will include recommendations concerning appropriate method combinations, data density and data quality requirements.

The first project phase comprised the drilling of 24 wells. Four of them are screened in the underlying bedrock formation, the rest being completed as $6^{\prime \prime}$ wells in the overlying alluvial aquifer. All wells can be used as pumping and as monitoring wells. Fig. 2 shows their location in the northern (FIELD I) and the southern (FIELD II) part of the experimental site.

At present, more than half of the wells have been tested. The resulting transmissivity values range between $2.5 * 10^{-2}$ and $4.0 * 10^{-2} \mathrm{~m}^{2} / \mathrm{s}$ yielding high groundwater fow velocities of up to $10 \mathrm{~m} / \mathrm{d}$. It should be noted however, that there is a high vertical variation in the velocity profile. The research program therefore emphasizes a detailed three-dimensional underground investigation within the experimental site.

Due to the high aquifer transmissivities, the observed drawdowns are generally small, especially in distant observation wells. Therefore, accurate unsteady-state measurements can only be obtained using automatic data-logging equipment. The system comprises a magnetic-inductive flowmeter and up to 5 pressure transducers with a resolution of better than $0.1 \mathrm{~cm}$ and a maximum sampling rate of one reading per second. Using a portable computer, a preliminary evaluation of the data can be performed directly in the field.

Twenty out of the 24 wells were cored from top to bottom. The undisturbed cores have been tested in specially constructed double-wall permeameters with a sample length of $25 \mathrm{~cm}$. Fig. 3 shows some results from the three neighbouring wells P9, P10, and P14. Even though there is a high variability in the measured values, two high permeability zones between 5.80 and $6.00 \mathrm{~m}$ and between 6.50 and 6.80 meters could be identified in all three wells.

Sieve analyses are subsequently performed on all permeameter samples. In case of notable layering the sample length is reduced down to $10 \mathrm{~cm}$. It should be mentioned that, depending on the calculation method used, the hydraulic conductivities obtained from sieve analyses differ by an order of magnitude from the permeameter measurements. 


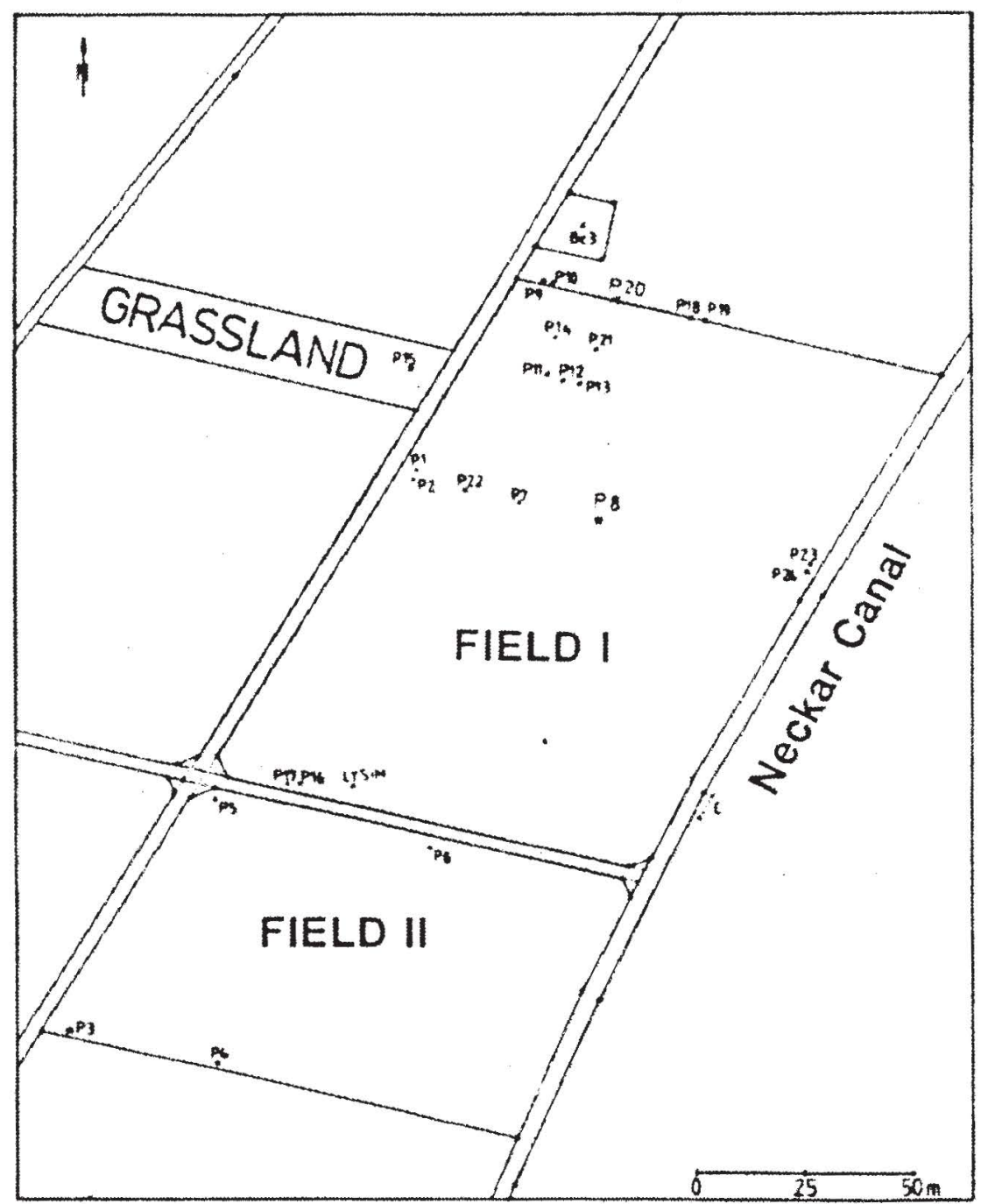

Fig. 2. Groundwater observation wells on the "Horkheimer Insel" experimental site.

Puits d'observation des eaux souterraines sur le site expérimental "Horkheimer Insel".

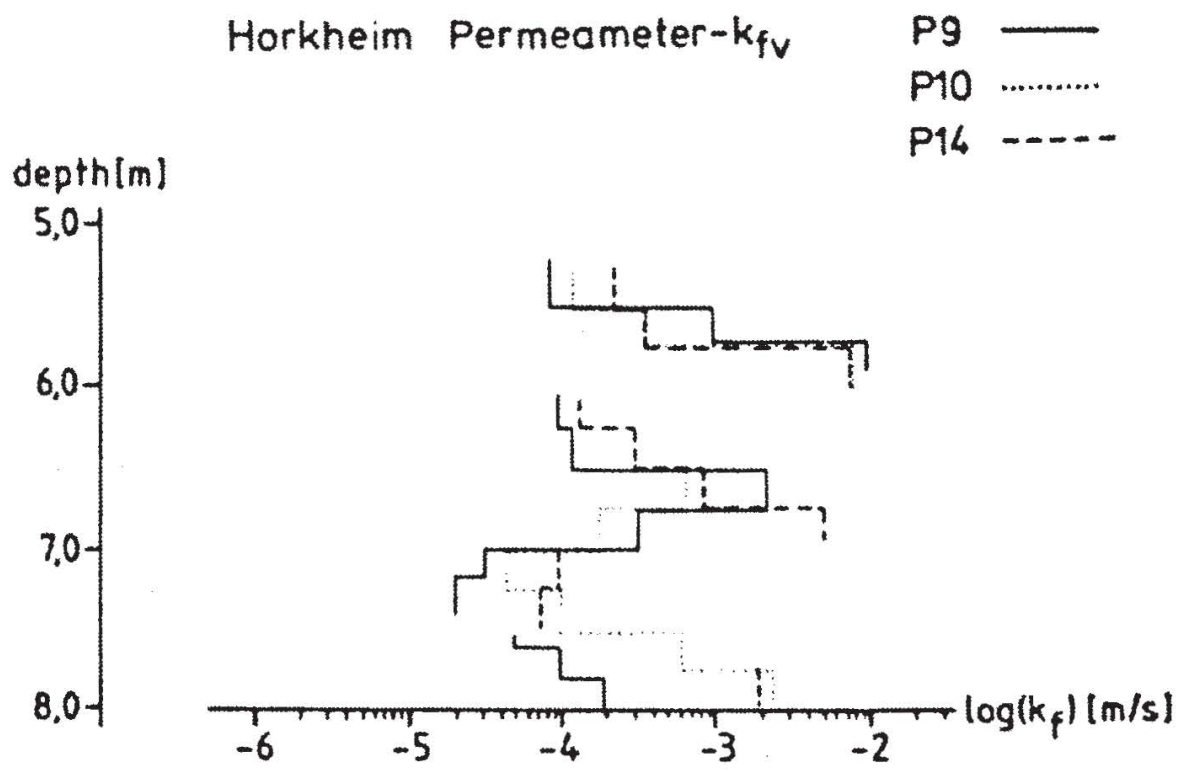

Fig. 3. Permeameter measurements - wells P9, P10, and P14.

Mesures au moyen de perméamètre - puits $\mathrm{P9}, \mathrm{P} 10$ et P14. 
The permeability profiles obtained from the cores and the pumpingtest results are used for a three dimensional analysis of the hydraulic conductivity variability throughout the experimental site. In the next project phase a number of natural and forced gradient tracer tests will be performed at the "Horkheimer Insel" test site. These tracer tests will be used to determine groundwater flow velocity profiles which will then be compared with the hydraulic conductivity profiles obtained from laboratory measurements.

For this purpose, a special multilevel sampler, the In-Line-Packer-System (ILPS), was developed to measure vertical concentration profiles using the existing fully screened observation wells [4]. One or more packer modules are inserted into the well and inflated to avoid vertical water circulation within the well. Numerous sampling points as close as $10 \mathrm{~cm}$ can be fitted to the elastic packer membrane. The sample inlets are either connected to a pump or a suction tube. To avoid vertical flow within the gravel pack the sampling points can be operated simultaneously. Fig. 4 shows the ILPS after installation in a fully screened observation well.

The final phase of the project includes the development of a three-dimensional groundwater flow and transport model for the test site area. This model will take into account not only the

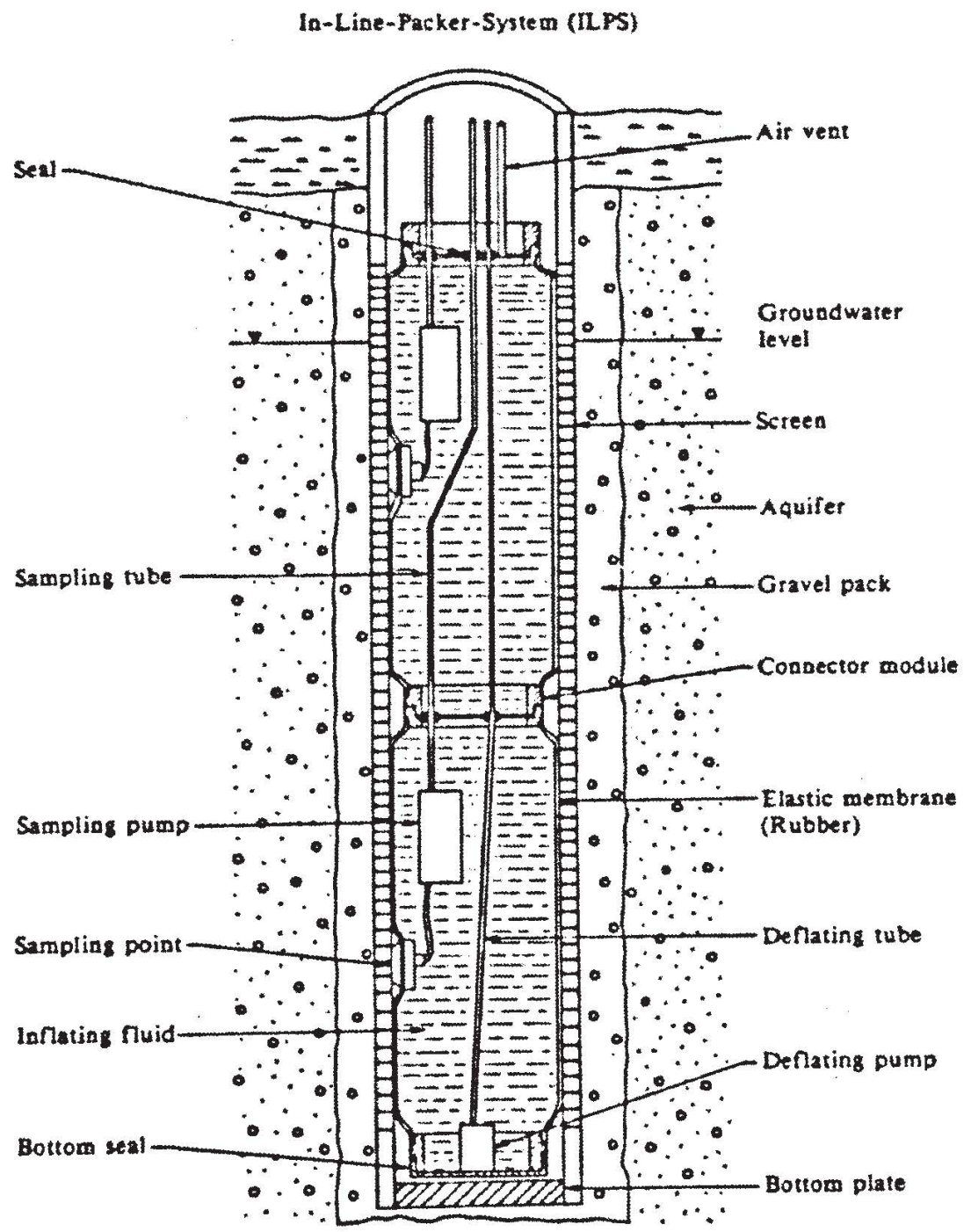

Fig. 4. In-Line-Packer-System (ILPS) installed in a fully screened observation well. Système de packer en ligne installé dans un puits dobservation à crépine continue. 
measured hydrogeological and hydromechanical parameters but also their geostatistical properties. This model will ultimately be coupled with the unsaturated zone models developed by the soil scientists. Together, this will allow a unsaturated-saturated simulation for the fate and transport of the agro-chemicals applied at the experimental site.

Transport processes and water quality in the unsaturated zone employing conventional and sustainable farming techniques (Institutes at the University of Hohenheim and Institut für Radiochemie, University of Karlsnthe - two projects).

Todays farming requires the use of fertilizers and pesticides. Depending on product mobility, persistence and soil conditions these chemicals may accumulate in the upper soil zone and subsequently percolate to the groundwater surface. Therefore, the environmental aspects of farming, especially the possible threat to groundwater quality, have recently received increased attention. Consequently, a number of agricultural research projects focus on the development and optimization of practical and economical solutions to minimize the application and percolation of agro-chemicals into the underground.

For the "Horkheimer Insel" field experiment a corn/winter-wheat crop rotation was selected. Two fields are operated in parallel for comparison purposes. In FIELD I standard farming techniques are employed using common quantities of pesticides and fertilizers. In FIELD II lower quantities of agro-chemicals are applied with reduced tillage. Table 1 summarizes the farming techniques employed on the two fields.

Table 1. Farming techniques as employed on the conventional and the sustainable field Techniques culturales employees sur le champ conventionnel et sur le champ à technique alternative

\begin{tabular}{ll}
\hline FIELD I (conventional agriculture) & FIELD II (sustainable agriculture) \\
\hline 1. Areal application of fertilizers and herbicides & 1. Row application of fertilizers and herbicides \\
2. High amounts of N-fertilizer & 2. Reduced N-fertilization \\
(e.g. $200 \mathrm{~kg} \mathrm{~N} / \mathrm{ha}$ for corn) & (120 kg N/ha for corn) \\
3. Conventional soil tillage & 3. Reduced soil tillage \\
(e.g. with fall ploughing) & (no ploughing) \\
& 4. Combined mechanical and chemical weed \\
& 5. Montrol
\end{tabular}

It is believed, that due to the additional measures taken, the longterm leaching of $\mathrm{N}$-fertilizer and of herbicides will be considerably reduced underneath FIELD II.

During the first project phase considerable effort went into the experiment design, the instrumentation and the characterization of the site. The instrumentation includes a weighable monolith lysimeter, a meterological station, numerous tensiometers and suction cups, partially equipped with automatic data-loggers.

Besides continuous registration, soil samples from depths of up to 4 meters are regularly analysed in the laboratory. The soil water is extracted from the samples using a ultracentrifuge and analysed for major ions, DOC, pll and electrolytic conductivity.

Fig. 5 shows nitrate concentrations in pore water versus depth obtained in November 1988 from FIELD I (conventional), FIELD II (sustainable) and a reference grassland. The two experimental fields are in operation for slightly more than one year. Yet, the measured nitrate concentrations already show significant differences. Peak concentrations are seven times Jower underneath 


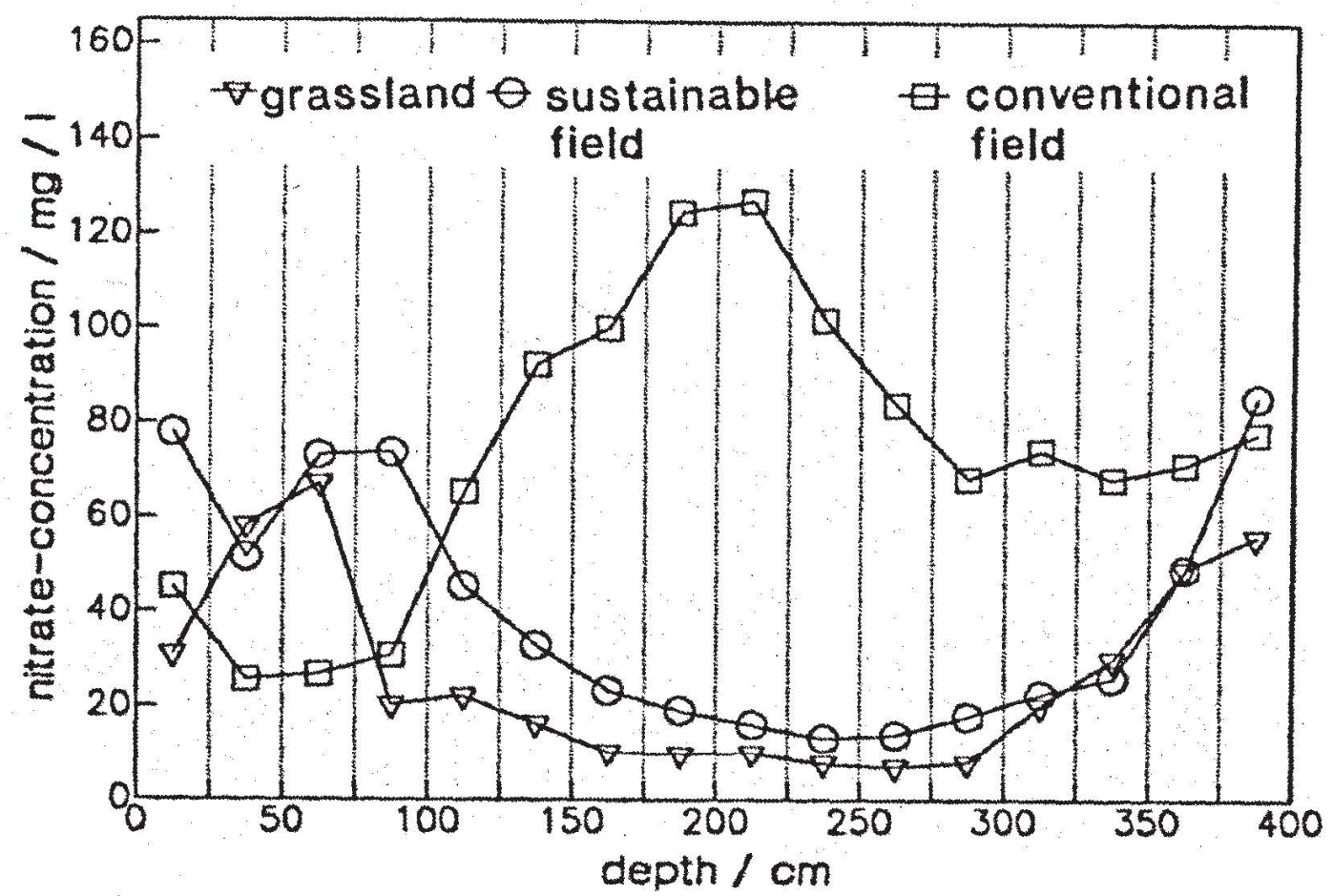

Fig. 5. Nitrate concentrations versus depth (November 9, 1988).

Concentrations en nitrate en fonction de la profondeur ( 9 novembre 1988).

FIELD II, indicating a remarkable improvement of the soil water quality. This becomes even more promising when considering the corn yields of $7600 \mathrm{~kg} / \mathrm{ha}$ in FIELD I as compared to 7200 $\mathrm{kg} / \mathrm{ha}$ on FIELD 11 .

Total $\mathrm{NO}_{3}-\mathrm{N}$ as estimated based on the measured soil moisture and concentration profiles and assuming an average soil density of $1500 \mathrm{~kg} / \mathrm{m}^{3}$ is shown in Table 2. Considering the entire profile, the values for the sustainable field are $42 \%$ lower than for the conventional field. Total $\mathrm{NO}_{3}-\mathrm{N}$ between $100 \mathrm{~cm}$ and $400 \mathrm{~cm}$ below ground is even $65 \%$ lower underneath the sustainable than underneath the conventional field.

Table 2. Calculated tolal $\mathrm{NO}_{3}-\mathrm{N}$ (November 9,1988$)$

Total calculé en $\mathrm{N} \cdot \mathrm{NO}_{3}(9$ novembre 1988)

\begin{tabular}{lll}
\hline & \multicolumn{1}{c}{ total NO$-\mathrm{N}$} & \\
\cline { 2 - 3 } & $010400 \mathrm{~cm}$ & 100 to $400 \mathrm{~cm}$ \\
& {$[\mathrm{~kg} / \mathrm{ha}]$} & {$[\mathrm{kg} / \mathrm{ha}]$} \\
\hline FIELD I (conventional) & 190 & 170 \\
FIELD Il (sustainable) & 110 & 60 \\
Grassland (no cultivation) & 60 & 25 \\
\hline
\end{tabular}

The change of $\mathrm{NO}_{3}$-concentrations over time is shown in Fig. 6 for the conventional field. The depth-profiles were obtained during three measuring campaigns in winter 1988/1989. Between November and December the peak moved downwards by about $40 \mathrm{~cm}$. The February profile indicates an increased nitrate input in the uppermost meter together with a general increase in the concentrations below $250 \mathrm{~cm}$. 


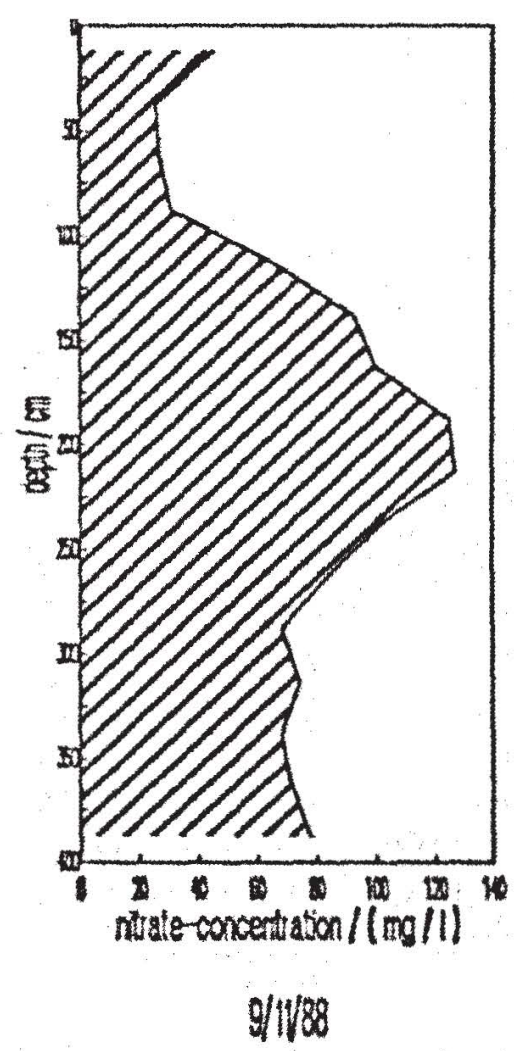

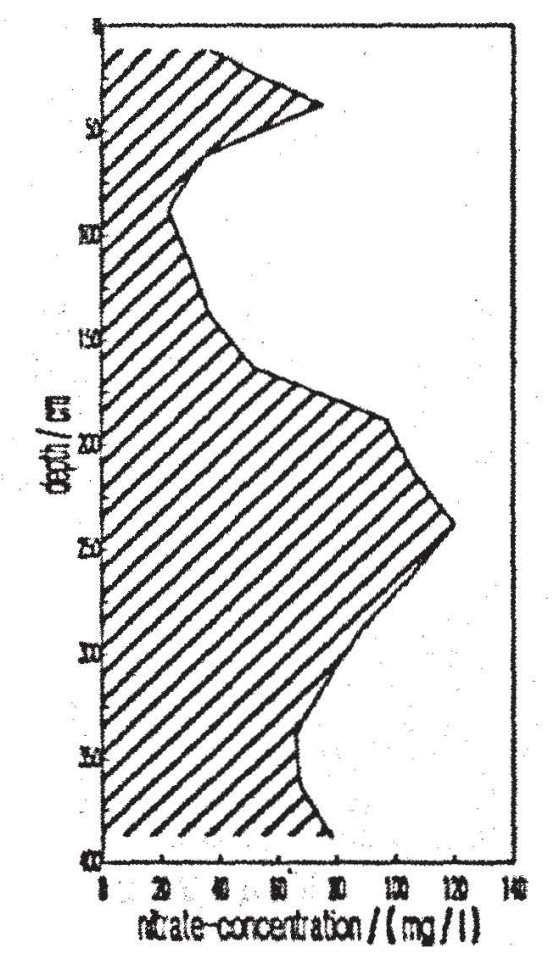

$2 / 2 / 180$

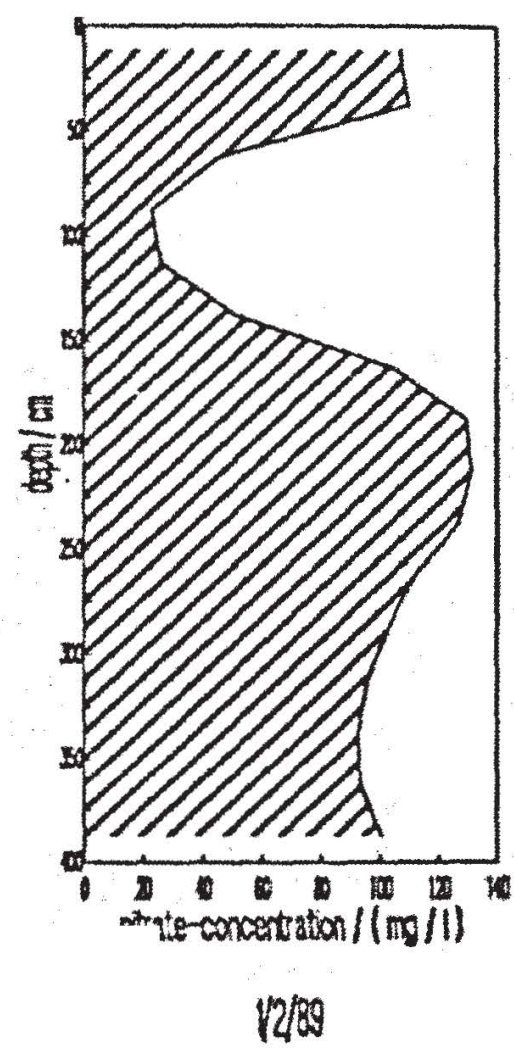

Fig. 6. Nitrate concentration depth-profiles underneath FIELD I (November 9, 1988, December 22, 1988, and February 1, 1989).

Profil des concentrations en nitrate sur le CHAMP I (9 novembre 1988, 22 décembre 1988 et 1 fébrier 1989).

Further interpretation has to consider not only the water movement but also nitrification-denitrification processes. Fig. 7 shows the anion distribution depth-profiles in November 1988 as measured underneath all three test sites, $\mathrm{It}$ is seen that the high nitrate concentrations at a depth of $200 \mathrm{~cm}$ underneath the conventional field are replaced by an increased bicarbonate concentration underneath the sustainable field and an increased bicarbonate and sulfate concentration underneath the grassland. The increased bicarbonate and sulfate concentrations give strong evidence to significant denitrification underneath the grassland and the sustainable field. Similar differences as observed for nitrate are expected for the pesticide concentrations. However, regular sampling and analysis is more time consuming and more expensive. The required laboratory capacities have recently been installed at the University of Hohenheim and are expected to be operational by mid 1989.

The next project phase comprises the installation of a second large lysimeter on the sustainable field (FIELD II), and an extension to the tensiometer and suction cups instrumentation network. Parallel to the field work, a number of mathematical models for the simulation of crop growth, unsaturated flow, as well as nitrate and pesticide transport are being developed. 


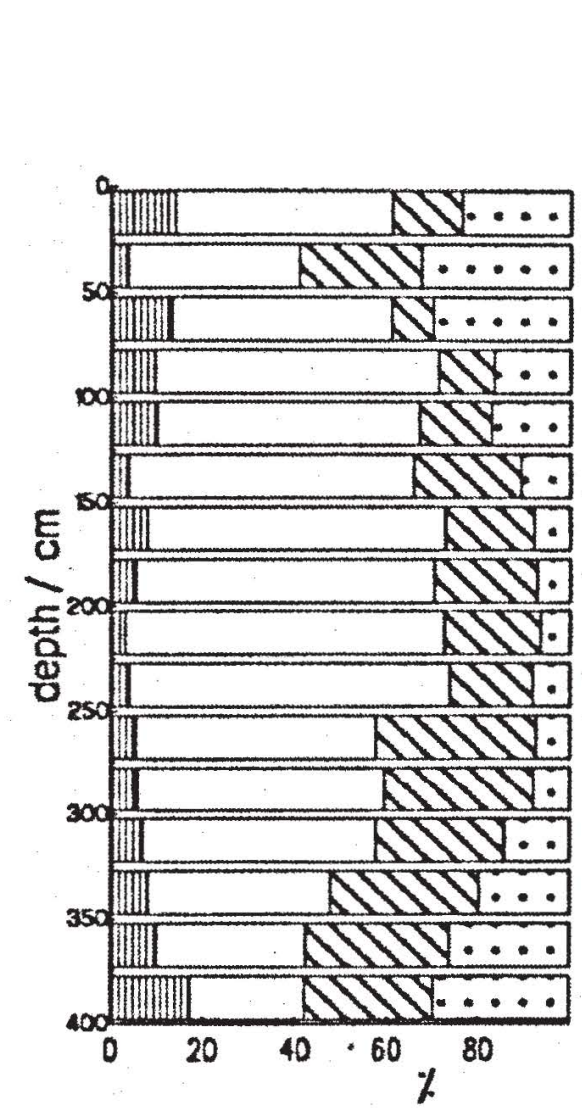

grassland

监 Chlorid $\square$ ico3 $\triangle$ Suffat

QNitrat

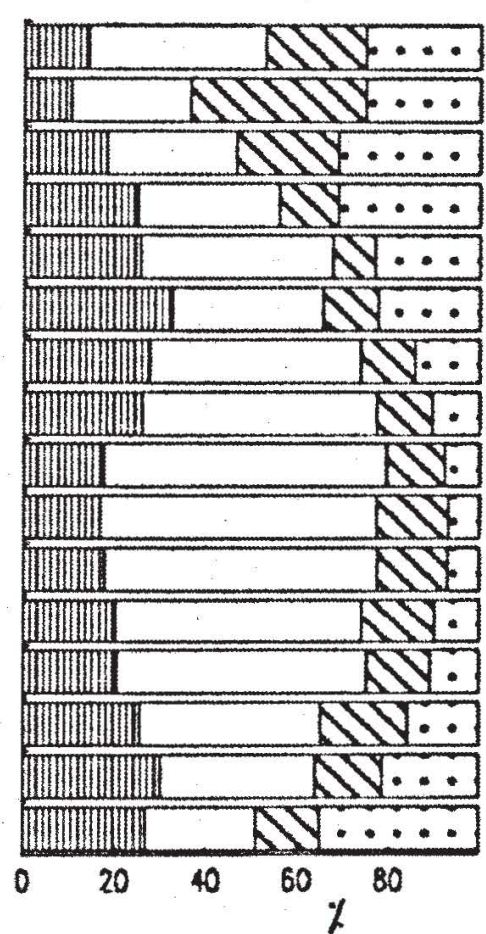

sustainable field

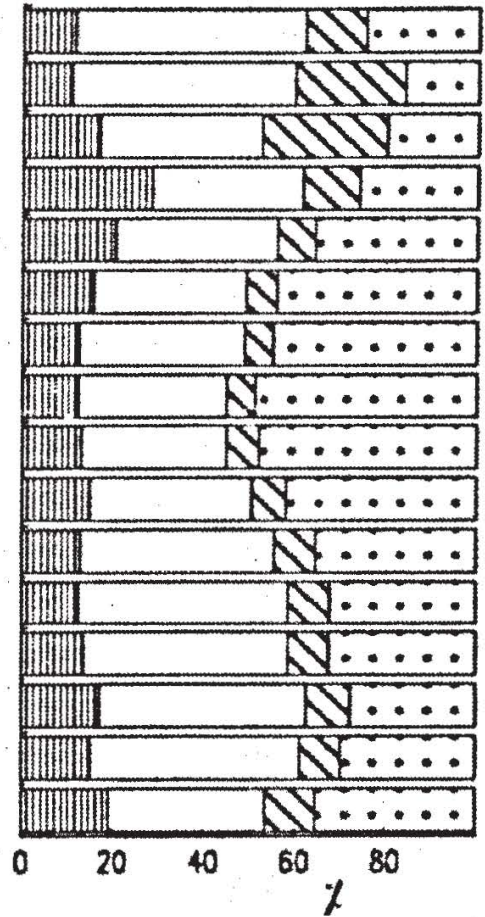

conventional field

Fig. 7. Anion distribution depth-profiles for FIELD 1, II and grassland (November 9, 1989).

Profil de la distribution en anions pour les CHAMPS 1, II et enherbé (9 novembre 1989).

Development of a distributed database system dedicated to environmental data requirements (Institut für Informatik, University of Stuttgart)

A complex interdisciplinary" research program requires good communication facilities. Oral communication is usually well organized; however, the data-administration and data-exchange is often neglected. Experience shows, that after the completion of a project either part of or sometimes even the entire raw data is lost. It was therefore decided to employ a distributed data storage, administration and retrieval system for the "Horkheimer Insel" field site.

This system should be flexible enough to allow for possible future data structure changes. It should also guarantee longterm data-security and data-consistency. The distributed database system is designed to provide full access to all raw data measured in the field and the laboratory, as well as to the processed and interpreted data.

In the first phase of the project, the required hard-and software had to be installed at the participating institutes. The UNIX workstations are connected via local and wide area networks, providing easy and reliable access to all sites. A commercially available SQL (Structured Querly Language) based relational Database Management System (DBMS) is installed at each node of the network. This commercial system is being extended considerably in order to fulfill the special 
data requirements of an environmental research project [2]. Some major differences between environmental and commercial data are summarized as follows:

1. Any single measurement is related to a specific time, a specific location and a specific measuring device. The data does not age and is altered only in case of measurement errors.

2. Environmental data are measured as discrete values of a continuous process. In the DBMS only these discrete values are stored. Therefore, appropriate time and space interpolation procedures have to be provided to allow continuous data queries.

3. Time-dependent environmental data cannot be reconstructed in case of data loss. Therefore, special data-security and backup procedures have to be employed.

To allow network wide data access without overloading the time-shared university and public networks a data replication concept is employed. Each node holds original data, i.e. data which is administered at that specific node and so called replicated data. Original data can be entered and modified at one site only but can be copied to other sites where it becomes replicated data. To guarantee network wide data integrity, the DBMS maintains a list of all data-sets together with the access rights for each node, i.e. an extended data-dictionary. Fig. 8 shows the data flow during replication update, which is performed on the base of the so called separated log files.

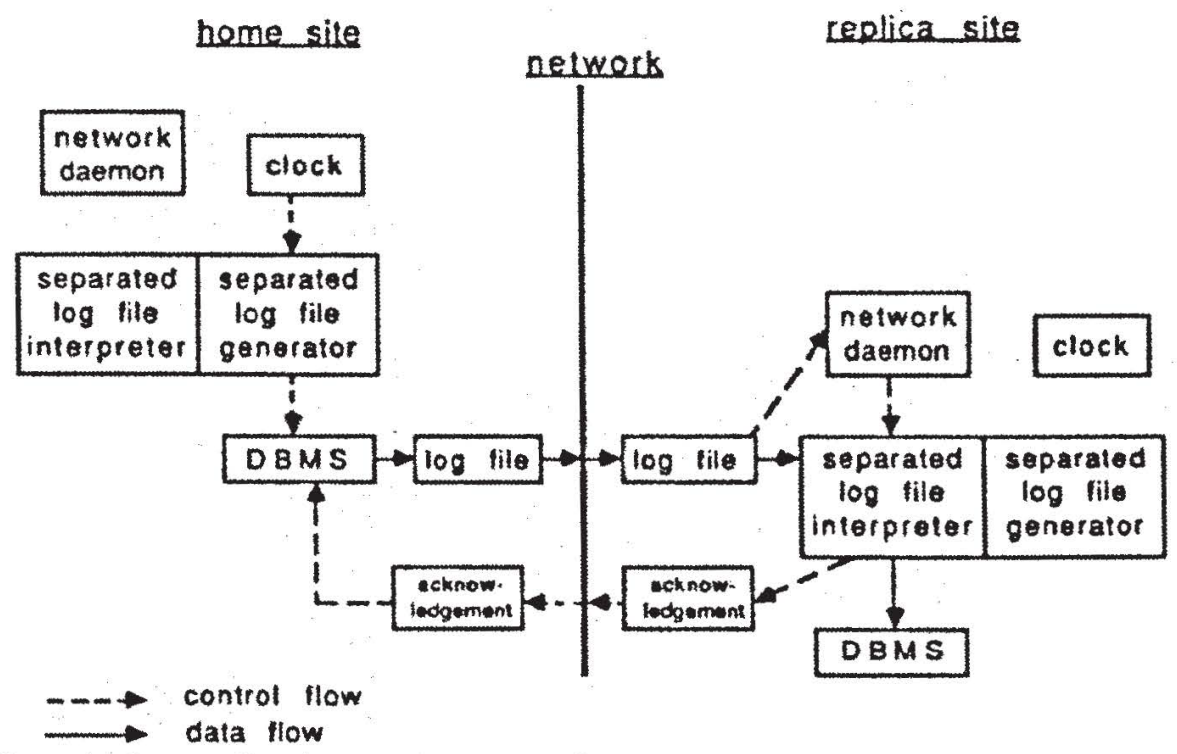

Fig. 8. Data flow during replication update.

Transfert de données durant le processus de duplication avec mise à jour ("replication update").

The next project phase comprises the network wide implementation and support of the distributed database system, including the tools presently under development. Furthermore, it is anticipated to extend the database concept to include an interface to a commercial Geographical Information System (GIS) which will be used for the processing and graphical display (maps) of space related data. 


\section{Acknowledgements}

The presented research program is conducted by an interdisciplinary group of more than a dozen scientists from various university institutes. The authors wish to thank the responsible project managers B. E. Allison, S. H. Eberle, G. Kahnt, R. R. van der Ploeg and A. Reuter for their contributions to this overview paper.

\section{References / Bibliographie}

1. KoBus, H., Das PWAB-Testfeld Wasser und Boden, Berichtsband zum 1. Statuskolloquium des PWAB Projekt Wasser-Abfall-Boden, Kernforschungszentrum Karlsruhe, 1988.

2. Neugebauer, L., Database-Support for a Long-Term Environmental Research Project, (submitted for publication).

3. Teutsch, G. and Prax, T., Vorstudie zur Überprüfung der Realisierungsmöglichkeiten für ein Demonstrationsprojekt Wasser und Boden, Wissenschafticher Bericht HWV 076, Institut für Wasserbau, Universität Stuttgart, 1987.

4. Teutsch, G. and Prak, T., The In-Line-Packer-System: A Modular Multilevel Sampler for collecting undisturbed Groundwater Samples, Proceedings IAHR, Intern. Symposium on Contaminant Transport in Groundwater, Stuttgart, 1989. 